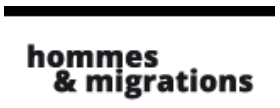

\section{Hommes \& migrations}

Revue française de référence sur les dynamiques

migratoires

1317-1318 | 2017

L'Europe en mouvement

\title{
Le paradoxe européen
}

\section{Marie Poinsot}

\section{CpenEdition \\ Journals}

\section{Édition électronique}

URL : http://journals.openedition.org/hommesmigrations/3861

DOI : 10.4000/hommesmigrations.3861

ISSN : 2262-3353

\section{Éditeur}

Musée national de l'histoire de l'immigration

\section{Édition imprimée}

Date de publication : 1 avril 2017

Pagination : 1

ISBN : 978-2-919040-38-4

ISSN : $1142-852 X$

\section{Référence électronique}

Marie Poinsot, «Le paradoxe européen », Hommes \& migrations [En ligne], 1317-1318 | 2017, mis en ligne le 01 avril 2017, consulté le 23 septembre 2020. URL : http://journals.openedition.org/ hommesmigrations/3861; DOI : https://doi.org/10.4000/hommesmigrations.3861 


\section{LE PARADOXE EUROPÉEN}

par MARIE POINSOT, rédactrice en chef.

\section{(1)}

L'exposition Ciao Italia, produite par le Musée national de l'histoire de l'immigration, présente depuis mars 2017 " un siècle d'immigration et de culture italiennes en France ". À cette occasion, Stéphane Mourlane, historien et l'un des co-commissaires de cette exposition, avait proposé de coordonner en duo avec le géographe Hadrien Dubucs un numéro de la revue Hommes \& Migrations qui fasse le point sur les migrations intra-européennes d'aujourd'hui.

On a oublié que les migrations, essentiellement européennes jusqu'à la fin du XXe siècle, ont marqué les grandes étapes de l'histoire de l'Europe. Que ce soit la fondation des routes commerciales, des grandes villes et des ports, l'industrialisation massive des économies et la reconstruction après les grandes guerres, ces transitions ont suscité un appel récurrent de main-d'œuvre par-delà des frontières internes au continent. L'Europe s'est aussi construite à travers l'histoire des échanges scientifiques, techniques et artistiques pour devenir le continent des découvertes et des innovations. L'accueil des proscrits, des réfugiés, des exilés a également concrétisé les idées de liberté, de droits de l'homme et de démocratie dans les pays européens.

La question qui ouvre ce dossier est celle de la continuité des flux des dernières décennies par rapport aux migrations européennes antérieures : à l'instar des immigrés italiens partis vers d'autres horizons dans le Nord de l'Europe dès le $\mathrm{XIX}^{\mathrm{e}}$ siècle, la cartographie des migrations internes montre que les profils des migrants ont changé. Le visage majoritaire est celui d'une élite, d'une population jeune et diplômée, à fort capital social et culturel, initiée aux rouages des carrières internationales. Pourquoi cette "Europe en mouvement » se réduit-elle à une minorité de $3 \%$ de la population du continent? Cette composante sociologique tranche avec l'autre Europe, celle de la marginalité éloignée de la mobilité européenne et qui se radicalise par des mouvements eurosceptiques. Mais les migrations décryptées ici montrent des réalités plus complexes et contrastées en fonction de la géopolitique des pays d'émigration ou d'immigration. Sur fond commun de transition économique, la désindustrialisation, le chômage et la précarité sociale génèrent de l'hostilité et du nationalisme xénophobe quand les migrants originaires des pays les plus pauvres de l'Europe sont associés aux «menaces » du libéralisme le plus radical.
Dans un contexte de crise européenne, l'anniversaire des soixante ans du traité de Rome et les trente ans du programme Erasmus rencontrent en 2017 peu d'intérêt. La revue y a pourtant vu l'occasion de mettre en relation la construction européenne et l'evolution des mobilités intraeuropéennes. Conçus par les coordinateurs du dossier, trois entretiens auprès de personnalités investies dans la construction européenne nous incitent à réfléchir aux liens entre liberté de circulation, citoyenneté et identité européennes. Si la construction européenne a permis l'essor des circulations internes, celles-ci sont encore peu connues et peu valorisées dans les opinions nationales. Pourtant, elles ont été conçues par les fondateurs de l'Europe comme un des moyens d'assurer une paix durable, en favorisant les échanges humains et le rattrapage des pays du Sud et de l'Est par l'harmonisation des économies à l'échelle européenne. Plus récemment, l'accord de Schengen signé en 1985 a focalisé l'Europe sur les mécanismes de contrôle des frontières et de régularisation des migrations externes. Ces politiques sécuritaires ont fini par se reporter sur les migrations originaires des pays plus récemment entrés dans l'Union au nom de la préférence nationale. Si le traité de Rome a instauré la liberté de déplacement comme condition de la citoyenneté européenne, en autorisant le séjour, le travail et la participation aux élections locales pour tous les Européens installés ailleurs, le statut d'étranger dans la réglementation commune a été maintenu, de peur que les législations nationales ne puissent plus assurer le contrôle sur les migrations dans leur ensemble. Les frontières internes ont été abolies. Les contrôles administratifs persistants ont freiné les installations de migrants dans des pays tiers, au profit de mobilités pendulaires, spécialisées selon la facilité des statuts ou les opportunités du moment.

L'Europe s'est donc construite sur des valeurs d'ouverture et d'humanisme, mais son incapacité à diffuser un discours positif sur son histoire migratoire a encouragé des discours politiques et médiatiques fondés sur des idéologies extrêmes. "L'Europe des valeurs est quasi-absente » nous dit Catherine Lalumière qui constate l'utilisation cynique du thème des migrations à des fins électoralistes dans la majorité des pays européens. Faute de quoi, l'Europe se prive d'arguments pour faire des migrations internes l'une des richesses du continent. 